\title{
Contato Interpessoal e Crenças sobre Homossexualidade: Desenvolvimento de uma Escala
}

\author{
EIder Cerqueira-Santos \\ Fernanda dos Santos Winter \\ Luís Adriano Salles \\ José Luís Longo \\ Universidade Federal do Rio Grande do Sul \\ Maycoln L. M. Teodoro \\ Universidade do Vale dos Rios dos Sinos
}

\begin{abstract}
RESUMO
Este estudo teve como objetivo criar uma escala de crenças sobre comportamentos de homossexuais para estudantes universitários e investigar a relação do contato interpessoal com as crenças sobre homossexualidade. Os participantes foram 442 universitários, 42,5\% homens ( $n=188$ ) e 57,5\% mulheres $(n=254)$, cuja média de idade foi de 21,6 anos $(d p=4,0)$. O instrumento foi composto de um questionário com 29 itens em forma de escala Likert, variando de 1 (concordo inteiramente) a 5 (discordo inteiramente), sobre comportamento de gays e lésbicas. As mulheres relataram mais amizade com homossexuais $(\underline{Z}=4,69 ; \underline{p}<0,001)$. Análises fatoriais mostraram um modelo de três fatores - representação negativa de gays e lésbicas $(\alpha=0,89)$; representação positiva $(\alpha=0,69)$; e, diferenciação intergrupal entre gays e lésbicas $(\alpha=0,69)$. A solução fatorial explicou 45,7\% da variância. Os homens, em comparação com as mulheres, obtiveram maior escore no primeiro fator e menor escore no segundo. Não foi encontrada diferença significativa no terceiro fator. Contato interpessoal foi negativamente correlacionado com representações negativas.
\end{abstract}

Palavras-chave: orientação sexual; preconceito; contato interpessoal.

\begin{abstract}
Interpersonal Contact and Beliefs about Homosexuality: Scale Development

The aim of this study was to create a scale to measure the beliefs held by Brazilian college students about gay and lesbian behaviors. In addition, the relationships between beliefs about homosexuality and one's interpersonal relationship with gays and lesbians were analyzed. Participants included 442 college students, $42.5 \%$ men $(n=188)$ and $57.5 \%$ women $(n=254)$, with a mean age at 21.6 years (SD = 4.0). The instrument was a questionnaire composed by 29 items rated on a five-point Likert scale about gay and lesbian behaviors. The results indicate that women reported having more friendships with homosexuals than men $(\underline{Z}=4.69 ; \mathrm{p}<0.001)$. Factor analyses showed revealed a three factors model: negative representation of gays and lesbians $(\alpha=.89)$; positive representation $(\alpha=.69)$; and within group differences of gays and lesbians $(\alpha=.69)$, explaining $45.7 \%$ of the variance. Men scored higher in the first factor and lower in the second, compared to women. There was no significant difference in the third factor. It was found that interpersonal contact is negatively correlated to negative beliefs about gays and lesbians.
\end{abstract}

Keywords: sexual orientation; prejudice; interpersonal contact.

Há mais de cinqüenta anos, especialmente no meio científico, questões concernentes à orientação sexual são tratadas sob a perspectiva de que a sexualidade não está vinculada a uma lógica binária. Neste sentido, a contribuição de Kinsey, Pomeroy e Martin
(1998/1948) foi de fundamental importância para que o comportamento sexual humano fosse concebido num continuum que extrapola categorias dicotômicas de homossexualidade e heterossexualidade. Para Herek (2000), esta forma de encarar a sexualidade humana 
impôs novas reflexões acerca dos papéis sexuais na nossa sociedade.

A despeito dessa flexibilização e das conquistas que vêm sendo obtidas por gays, lésbicas, bissexuais e transgêneros, o preconceito existente em relação à orientação sexual não-dominante ainda é bastante evidente (Anjos, 2002; Hart \& Wellings, 2002) e, especialmente depois de a Associação Americana de Psiquiatria ter deixado de categorizar a homossexualidade como um distúrbio, em 1973, segue motivando investigações científicas (Herek, 1991, 2002; Meyer, 2003). Antes disso, porém, ainda na década de 60, o termo homofobia já era empregado como sinônimo de atitudes e comportamentos ofensivos a gays e lésbicas. Essa terminologia suscitou várias críticas, pois pressupõe que tais hostilidades derivam de algum tipo de medo irracional sentido por parte da maioria heterossexual, o que poderia ser compreendido a partir de um modelo de enfermidade e, portanto, passível de ser superado por via de tratamento, como ocorre com outras fobias (Herek, 2000).

Ainda sob essa perspectiva, as manifestações de preconceito, ratificado nas mais variadas práticas cotidianas das sociedades sexistas, perderiam grande parte de seu caráter social (Herek, 2002). É em função disso que a expressão "preconceito sexual”, definida por Herek $(2000,2004)$ como "atitudes negativas em relação a uma pessoa por causa de sua orientação sexual” parece mais adequada.

Obviamente, a cristalização de padrões para o exercício da sexualidade e a moral sexual dominante remetem essa expressão ao preconceito contra gays e lésbicas, embora ela não diferencie como alvos de hostilidade homossexuais, heterossexais ou bissexuais. A expressão, segundo o autor, não sugere, previamente, possíveis razões que possam explicar a origem ou a dinâmica das atitudes negativas, como ocorreria no caso de "homofobia". Pesquisas têm evidenciado que o preconceito sexual difere quantitativa e qualitativamente em função de a vítima ser um homem ou uma mulher homossexual (Engstrom \& Sedlacek, 1997; Kite \& Lamar, 1998).

Sobre a diferença de gênero quanto ao julgamento homossexual, alguns estudos têm relatado que os homens heterossexuais demonstram mais sentimentos negativos contra gays do que mulheres heterossexuais (D’Augelli \& Rose, 1990; Simoni, 1996; Yarber \& Lee, 1983). Isso está diretamente associado ao viés sob o qual são analisadas as estratégias para lidar-se com o preconceito, bem como à maneira como a própria homossexualidade é analisada frente a determinados padrões culturais (Williamson, 2000).

Tomadas pela via dos direitos aos homossexuais, e, portanto, partindo-se do princípio de que gays e lésbicas fazem parte de uma minoria oprimida - pode-se, aqui traçar um paralelo com as minorias étnicas essas estratégias permitem a defesa dos homossexuais como constituintes de um grupo homogêneo, vítima das mesmas formas de preconceito. Tal perspectiva vai de encontro à proposição de que gays e lésbicas são vítimas de preconceito de maneiras diferenciadas. Herek (2000; 2002) e Kite e Lamar (1998) salientam que mulheres heterossexuais geralmente apresentam um comportamento semelhante diante de gays e lésbicas, ao passo que homens heterossexuais são mais hostis com homens homossexuais do que com lésbicas. Pressupõe-se, dessa maneira, que as atitudes preconceituosas de homens heterossexuais alicerçam-se, sobremaneira, em questões de gênero e de identidade sexual. Por outro lado, o preconceito sexual de mulheres heterossexuais relaciona-se à percepção de que homossexuais constituem um grupo minoritário, salientando-se, em função disso, muito mais as questões de grupo do que as individuais.

Ressaltando outros aspectos, Whitley (2001) investigou o preconceito sexual pela perspectiva do sistema cultural de crenças de gênero (cultural gender belief system). Seu estudo atribui as atitudes em relação a homossexuais às crenças e opiniões culturalmente definidas sobre as qualidades concernentes a homens e mulheres e que diferenciam uns dos outros. $\mathrm{O}$ autor encontrou relação entre o sistema de crenças de gênero e a atitude em relação à homossexualidade, conferindo o preconceito sexual em parte ao desejo dos indivíduos heterossexuais de manter suas tradicionais distinções de gênero, que estariam sendo transpostas por gays e lésbicas.

O preconceito sexual, assim como ocorre com outras formas de preconceito, está fortemente relacionado ao contato interpessoal estabelecido entre o grupo minoritário (homossexuais) e o majoritário (heterossexuais). A hipótese do contato interpessoal (Allport, 1979) tem sido defendida como um intrumento de redução de atitudes negativas e conflitos contra minorias. Segundo Allport (1979), o contato regular com membros de um outro grupo pode promover a redução de estereótipos a partir do contato com novas informações sobre o grupo minoritário. Apesar da grande 
aceitação da proposta de Allport, estudos recentes têm investigado a influência de outras variáveis que podem potencializar o efeito do contato interpessoal, por exemplo, o fato de ter intimidade ou ser amigo (Brewer \& Miller, 1984; Liang \& Alimo, 2005; Wright, Aron, \& McLaughlin-Volpe, 1997).

Recentes estudos ressaltam que heterossexuais que mantêm contato com homossexuais, seja em sua própria família, seja com amigos ou conhecidos, são aqueles que manifestam menores níveis de preconceito, contribuindo para isso não apenas a proximidade com gays e lésbicas, como também a possibilidade de discutir com esses indivíduos questões relativas à orientação sexual (Herek, 2000, 2002). Em estudo com uma amostra norte-americana de heterossexuais, Herek e Capitanio (1996) investigaram a influência do contato interpessoal no preconceito em relação a homossexuais, distinguindo nesse grupo gays e lésbicas e enfatizando o número de pessoas desses grupos com quem os sujeitos mantinham contato. Os resultados revelaram que as atitudes de heterossexuais em relação a homossexuais eram tanto mais favoráveis quanto maior fosse o número de gays e lésbicas conhecido pelos entrevistados. Também surgiram como fatores de influência na atitude favorável o grau de intimidade mantido com gays e lésbicas e a revelação direta aos entrevistados da sua orientação sexual.

Os estudos relatados até aqui demontram esforços internacionais na exploração desta temática, mesmo que tenham enfoques diferenciados. Ressalta-se a tentativa de utilização de instrumentos de pesquisa apropriados e específicos para a investigação de variáveis de interesse, entre elas, o contato interpessoal (Herek, 2000, 2002; Liang \& Alimo, 2005).

No Brasil, apesar da importância desse tópico (Anjos, 2002), são poucos os estudos que tentam mensurar esses constructos. Lacerda, Pereira e Camino (2002), em uma pesquisa com estudantes universitários de João Pessoa, aplicaram uma escala de preconceito e encontraram diferença significativa entre o curso de origem do estudante universitário e o tipo de preconceito (flagrante, sutil ou inexistente), e entre o curso de origem e a explicação dada à homossexualidade. Constataram também que a principal ancoragem social para o preconceito contra homossexuais seria a explicação dada à homossexualidade, o que diferiria de um curso para outro.

A teoria do contato interpessoal (Allport, 1979) tem sido pouco explorada no contexto universitário brasileiro, revelando uma carência de escalas breves que sirvam de base para a investigação de outras variáveis que contribuem para o julgamentos e atitudes sobre a homossexualidade. O objetivo deste estudo foi, inicialmente, desenvolver uma escala capaz de avaliar crenças sobre homossexualidade. Em segundo lugar, buscou-se investigar as interações entre gênero e contato interpessoal com as crenças sobre homossexualidade numa amostra de universitários.

\section{MÉTODO}

\section{Participantes}

Os participantes foram 442 universitários, 42,5\% homens $(n=188)$ e $57,5 \%$ mulheres ( $n=254)$, cuja idade variou entre 17 e 30 anos, com média de 21,6 anos $(d p=4,0)$. Quanto à orientação sexual, 95,2\% se autodenominaram como exclusivamente heterossexuais; 3,9\% como bissexuais; e, 0,9\% como exclusivamente homossexuais. No entanto, 6,6\% dos participantes declararam sentir-se atraídos sexualmente por pessoas do mesmo sexo. Os participantes foram convidados a participar voluntariamente do estudo, sendo $24 \%$ oriundos de cursos das ciências humanas e sociais, $29 \%$ das ciências exatas e $47 \%$ das ciências biológicas e saúde.

\section{Instrumentos}

A coleta de dados foi realizada por meio de um questionário composto por duas partes: Dados sóciodemográficos, escala de atração sexual e de orientação sexual (DeSouza, Solberg, \& Cerqueira-Santos, 2007) e Escala Likert de Crenças sobre a Homossexualidade.

Questionário Sócio-demográfico: Os participantes responderam a um questionário com nove questões sócio-demográficas relativas à idade, sexo, estado civil, curso, ano do curso, grupo étnico/racial, orientação sexual, atração sexual, quantidade de colegas homossexuais e freqüência de contato com homossexuais.

Escala de Atração Sexual e de Orientação Sexual (DeSouza, Solberg, \& Cerqueira-Santos, 2007): Composta por quatro questões, trata-se de uma escala tipo Likert para indicação de atração e envolvimento sexual com o sexo oposto e mesmo sexo.

Escala de Crenças sobre Homossexualidade $(E C H)$ : A escala foi composta de 29 itens tipo Likert variando de 1 (concordo inteiramente) a 5 (discordo inteiramente), com o mesmo número de afirmações 
positivas e negativas sobre a homossexualidade masculina e feminina. Os itens foram desenvolvidos a partir de entrevistas com gays, lésbicas e heterossexuais, assim como a partir de discussões com participantes destes grupos e de revisões da literatura. Três juízes participaram da escolha dos itens e foi realizada uma aplicação piloto da versão do instrumento.

Os itens foram organizados em três fatores hipotéticos com base teórica (Bowen \& Bourgeois, 2001; Kite \& Lamar, 1998; Williamson, 2000), sendo o Fator 1 denominado representação negativa sobre a homossexualidade (noções de origem e exercício da homossexualidade relacionadas à ideia de desvio e erro, com consequências negativas ao desenvolvimento da pessoa e suas relações interpessoais), o Fator 2 representação positiva sobre a homossexualidade (noção da homossexualidade como geradora de características positivas para a pessoa e suas relações interpessoais, como cartacterísticas de personalidade positivas e talentos “especiais”), e o Fator 3 distinção intragrupal sobre homossexuais (noção que os homossexuais não formam um grupo heterogêneo e de que carcterísticas negativas e positivas podem variar dentro do grupo de homossexuais).

\section{Procedimentos}

Os estudantes foram abordados em grupo por uma dupla de pesquisadores que aplicou o instrumento em sala de aula. Cada participante recebeu uma carta com os objetivos da pesquisa e um termo de consentimento livre e esclarecido. Os participantes foram instruídos verbalmente sobre o preenchimento do instrumento, cujo tempo médio para conclusão foi de 20 minutos. As respostas foram dadas individualmente e em sigilo. O estudo foi aprovado pelo Comitê de Ética em Pesquisa da UFRGS.

\section{Análise de Dados}

Os dados foram inseridos num programa estatístico pela mesma equipe de pesquisadores que foi treinada para a participação da coleta de dados. A análise foi realizada a partir de um modelo quantitativo utilizando-se o pacote SPSS 12.0 for Windows. Foram realizados: análise fatorial para a criação de um modelo fatorial para a Escala de Crenças sobre Homossexualidade, análise de consistência interna por meio do Alpha de Cronbach, Teste de Mann-Whitney e análises de variância univariada. Foram explorados os escores obtidos na escala de julgamento em relação às variáveis gênero e contato com gays e lésbicas.

\section{RESULTADOS}

\section{Contato Interpessoal}

Quanto à freqüência de contatos com gays e lésbicas, a maioria dos participantes relatou ter pouco contato $(38,0 \%)$ ou um contato moderado $(27,4 \%)$ com homossexuais. A Tabela 1 apresenta a distribuição considerando o gênero do participante. Entre os homens, 29,8\% relataram não ter nenhum contato com homossexuais e apenas $11,7 \%$ revelaram ter muito contato. Já para as mulheres, apenas 12,6\% disseram não ter nenhum contato, enquanto $16,9 \%$ afirmaram ter muito contato com homossexuais. A análise com o Teste de Mann-Whitney revelou que as mulheres têm significativamente mais contato com homossexuais quando comparadas aos homens $(\underline{Z}=4,69 ; \mathrm{p}<0,001)$.

Quanto ao número de amigos homossexuais, foram criadas quatro categorias: não tem amigos, tem um ou dois, tem três ou quatro amigos, e, tem cinco ou mais amigos. Para o total da amostra, 11,8\% disseram não ter nenhum amigo homossexual, enquanto que o restante da amostra tem, ao menos, uma pessoa homossexual considerada como amiga. Como esperado, um Teste de Mann-Whitney revelou que as mulheres têm um maior número de amigo(a)s homossexuais, como pode ser observado na Tabela $1(\underline{Z}=4,02 ; \mathrm{p}<0,001)$. 
TABELA 1

Grau de Contato e Amizades com Homossexuais por Gênero do Participante

\begin{tabular}{lccc}
\hline & \multicolumn{2}{c}{ Gênero } & Total \\
\cline { 2 - 3 } Contato com Homossexuais & Masculino & Feminino & F (\%) \\
\cline { 2 - 3 } Nenhum Contato & $56(29,8 \%)$ & $32(12,6 \%)$ & $88(19,9 \%)$ \\
Pouco Contato & $74(39,4 \%)$ & $94(37,0 \%)$ & $168(38,0 \%)$ \\
Contato Moderado & $36(19,1 \%)$ & $85(33,5 \%)$ & $121(27,4 \%)$ \\
Muito Contato & $22(11,7 \%)$ & $43(16,9 \%)$ & $65(14,7 \%)$ \\
\hline Amigos Homossexuais & & & \\
\hline Nenhum amigo & $32(17,0 \%)$ & $20(7,9 \%)$ & $52(11,8 \%)$ \\
1-2 amigos & $80(42,6 \%)$ & $87(34,3 \%)$ & $167(37,8 \%)$ \\
3-4 amigos & $43(22,9 \%)$ & $74(29,1 \%)$ & $117(26,5 \%)$ \\
5 ou mais amigos & $33(17,6 \%)$ & $73(28,7 \%)$ & $106(24,0 \%)$ \\
\hline
\end{tabular}

\section{Escala de Crenças sobre Homossexualidade (ECH)}

A análise fatorial exploratória da escala (ECH) foi feita com o método de extração dos componentes principais e rotação Varimax. A decisão do uso de uma rotação ortogonal foi tomada após a verificação de ausência de correlação significativa entre os fatores, por meio da análise fatorial com rotação Oblimin. O critério adotado para seleção do número de fatores foi o gráfico Scree Plot (vide Figura 1). Todos os autovalores dos fatores selecionados ficaram acima de 2
(Fator 1 = 6,46; Fator $2=2,65$ e Fator $3=2.33$ ). $\mathrm{O}$ índice de Kaiser-Meyer-Olkin confirmou a adequação do modelo para três fatores $(\mathrm{KMO}=0,712)$. Na Tabela 2 encontram-se os itens com suas respectivas cargas fatoriais e valor do Alpha de Cronbach para cada fator. A análise mostrou uma agregação consistente dos itens, seguindo a construção teórica da escala. A solução fatorial com três fatores explicou cerca de $45,7 \%$ da variância.

TABELA 2

Itens, Cargas Fatoriais e Índices de Consistência Interna da Solução Fatorial da Escala (ECH)

\begin{tabular}{lcc}
\hline Itens & Fator 1 & Fator 2 \\
$\alpha=0,89$ & $\underline{\alpha}=0,69$ & $\underline{\alpha}=0,69$ \\
\hline $\begin{array}{l}\text { Gays são sexualmente mais permissivos ("fáceis") do que homens } \\
\text { heterossexuais }\end{array}$ & 0,742 & \\
\hline Gays, em geral, são mais promíscuos do que homens heterossexuais & 0,727 \\
\hline Lésbicas usam mais drogas do que mulheres heterossexuais & 0,721 \\
\hline Gays usam mais drogas do homens heterossexuais & 0,718 \\
\hline Lésbicas, em geral, são mais promíscuas do que mulheres heterossexuais & 0,713 \\
\hline $\begin{array}{l}\text { Lésbicas são sexualmente mais permissivas ("fáceis") do que mulheres } \\
\text { heterossexuais }\end{array}$ & 0,698 \\
\hline $\begin{array}{l}\text { Relacionamentos entre gays são menos duradouros do que relacionamentos } \\
\text { heterossexuais }\end{array}$ & 0,674 \\
\hline Gays são menos fiéis que homens heterossexuais & 0,672 \\
\hline $\begin{array}{l}\text { Relacionamentos entre lésbicas são menos duradouros do que } \\
\text { relacionamentos heterossexuais }\end{array}$ & 0,672 \\
\hline Lésbicas são menos fiéis que mulheres heterossexuais & \\
\hline Lésbicas expõem-se mais a riscos de DST's e AlDS do que mulheres & 0,641 \\
\hline heterossexuais & 0,588 \\
\hline Lésbicas afastam-se de preceitos religiosos & \\
\hline Gays afastam-se de preceitos religiosos & 0,567 \\
\hline $\begin{array}{l}\text { Gays expõem-se mais a riscos de DST's e AlDS do que homens } \\
\text { heterossexuais }\end{array}$ & 0,565 \\
\hline
\end{tabular}




\begin{tabular}{|c|c|c|c|}
\hline Itens & $\begin{array}{c}\text { Fator } 1 \\
\underline{\alpha}=0,89\end{array}$ & $\begin{array}{c}\text { Fator } 2 \\
\underline{\alpha}=0,69\end{array}$ & $\begin{array}{l}\text { Fator } 3 \\
\underline{\alpha}=0,69\end{array}$ \\
\hline Lésbicas se esforçam mais para serem bem sucedidas profissionalmente & & 0,789 & \\
\hline Gays se esforçam mais para serem bem sucedidos profissionalmente & & 0,752 & \\
\hline Gays são pessoas criativas e divertidas & & 0,558 & \\
\hline Lésbicas são pessoas criativas e divertidas & & 0,538 & \\
\hline Gays são mais sensíveis do que homens heterossexuais & & 0,524 & \\
\hline $\begin{array}{l}\text { A infidelidade é mais comum entre homens, independentemente da sua } \\
\text { orientação sexual }\end{array}$ & & 0,489 & \\
\hline Lésbicas são mais sensíveis do que mulheres heterossexuais & & 0,410 & \\
\hline $\begin{array}{l}\text { Lésbicas masculinizadas são, em geral, mais discriminadas do que lésbicas } \\
\text { feminilizadas }\end{array}$ & & & 0,755 \\
\hline $\begin{array}{l}\text { Gays afeminados são, em geral, mais discriminados do que gays } \\
\text { masculinizados }\end{array}$ & & & 0,670 \\
\hline Gays passivos são mais afeminados do que gays ativos & 0,364 & & 0,569 \\
\hline Lésbicas passivas são mais afeminadas do que lésbicas ativas & 0,365 & & 0,546 \\
\hline
\end{tabular}

O primeiro fator, composto de 14 itens, foi nomeado Representação negativa de gays e lésbicas e obteve um índice de $25,8 \%$ da variância explicada $(\alpha=0,89)$. Este foi composto por sentenças com conotação negativa sobre a homossexualidade e os comportamentos homossexuais. O segundo fator, com sete itens que valorizam a conduta de homossexuais, foi denominado Representação positiva e explicou 10,5\% da variância $(\alpha=0,69)$. O terceiro fator, com quatro itens, foi chamado Diferença intragrupal de gays e lésbicas e obteve $9,3 \%$ da variância explicada $(\alpha=0,69)$. Este fator investiga a percepção sobre gays e lésbicas como um grupo não-homogêneo, por exemplo, gays afeminados versus gays másculos.

\section{Análise da Escala e sua Relação com o Gênero e 0 Contato com Gays}

Nesta parte das análises, foram avaliadas as diferenças e interações entre os escores obtidos na escala de crenças sobre homossexualidade divididos por gênero e freqüência do contato com gays e lésbicas. Para isto, foi feita uma série de análises de variância univariada para cada fator encontrado na escala (ECH). Nestas análises não foram incluídas a variável curso de origem do participante, pois ela não apresentou qualquer diferença significativa com relação à expressão do julgamento no fator $1(\mathrm{~F}=2,90 ; \mathrm{p}=0,06)$, no fator $2(F=2,48 ; p=0,08)$ e no fator $3(F=0,57$; $\mathrm{p}=0,56)$.

As análises univariadas (gênero $X$ freqüência do contato) para o fator 1 (Representações negativas) não mostraram interação significativa entre as duas variáveis independentes $(F=1,52, G L=3 ; p=0,20)$. Houve, no entanto, diferença significativa com relação ao gênero $(F=6,78, G L=1 ; p<0,001)$ e ao contato $(F=6,37$, $\mathrm{GL}=3$; $\mathrm{p}<0,001)$. Para o fator representações negativas, homens apresentaram escores significativamente superiores se comparados às mulheres. Análises post hoc com o Teste de Bonferroni mostraram que os participantes que afirmaram ter mais contato com gays e lésbicas demonstram menos julgamento negativo do que aqueles que afirmam ter pouco ou nenhum contato. Do mesmo modo, o índice de representações negativas dos participantes com pouco contato é superior ao das pessoas com moderado ou muito contato com gays e lésbicas.

As análises univariadas (gênero $X$ freqüência do contato) para o fator 2 (Representações positivas) indicaram uma forte tendência para a interação entre as variáveis independentes gênero e freqüência do contato $(\mathrm{F}=2,18, \mathrm{gl}=3 ; \mathrm{p}=0,08)$. Devido à possibilidade de interação, foram feitas comparações entre gênero separadas para cada grupo de freqüência de contato. Análises com os participantes que possuem pouco ou nenhum contato com gays mostraram que as mulheres apresentam escores mais elevados em representações positivas do que os homens. Por outro lado, não foi encontrada diferença significativa entre homens e mulheres que possuíam contato moderado ou intenso com gays e lésbicas, mostrando que o contato aparece como variável mais intensa do que gênero.

Finalmente, análises univariadas (gênero $\mathrm{X}$ freqüência do contato) para o fator 3 (Distinção intra- 
grupal) não apresentaram nenhum resultado significativo para gênero $(\mathrm{F}=0,68, \mathrm{gl}=1 ; \mathrm{p}=0,40)$, para contato $(\mathrm{F}=0,40, \mathrm{gl}=3 ; \mathrm{p}=0,75)$ ou interação entre as variáveis $(\mathrm{F}=0,63, \mathrm{gl}=3 ; \mathrm{p}=0,59)$.

\section{DISCUSSÃO}

A escala de crenças sobre homossexualidade (ECH) mostrou-se um instrumento adequado para a mensuração deste aspecto da representação sobre gays e lésbicas entre estudantes universitários. Apesar de a hipótese original conceber a escala com distribuição semelhante de itens para representações positivas e negativas, como esperado, a representação negativa mostrou-se mais acurada, criando-se um fator mais forte e com mais itens. Este resultado está de acordo com a literatura (Anjos, 2002; Hart \& Wellings, 2002; Whitley 2001), que demonstra uma consistência maior sobre as idéias negativas ligadas à homossexualidade. No entanto, o indíce do Alpha de Cronbach foi satisfatório para as representações positivas, o que torna a escala mais completa e inovadora nos estudos brasileiros sobre homossexualidade. O Fator 3, que revela uma postura mais ponderada em relação à homossexualidade mostrou-se confuso, uma vez que tal postura tende a uma representação positiva (Fator 1), o que é compreensivel ao considerar a noção de preconceito.

O primeiro dado levantado por este estudo ressalta a diferença de gênero para o grau de contato com pessoas homossexuais, apontando e confirmando o que é encontrado na literatura: as mulheres são mais abertas às relações com homossexuais (Herek, 2000, 2002; Liang \& Alimo, 2005). Como esperado, este resultado corrobora, principalmente em um país de cultura sexista como o Brasil, a hipótese de que o grau de preconceito é maior entre os homens quando comparados às mulheres. Theodore e Basow (2000) ressaltam que entre os homens heterossexuais há uma maior expectitaiva e cobrança quando ao desempenho da masculinidade, visando à satisfação dos padrões culturais, o que pode gerar manifestações hostis à homossexualidade (principalmente masculina) e uma tentativa de afastamento e desaprovação do grupo gay.

Do ponto de vista sócio-histórico (Green, 2000) entende-se que as relações entre homens e seus parceiros não-heterossexuais são permeadas por uma imaginária relação homoerótica. Ou seja, a cultura machista associa a este tipo de relação uma intenção sexual, mesmo que somente manifesta pelo indivíduo nãoheterossexual (em geral, um homossexual). A formação deste imaginário demonstra a representação criada especialmente para os homossexuais como uma categoria mais erotizada, provocando fuga e medo de avaliações dos pares heterossexuais masculinos e, por conseqüência, frágeis ou escassos laços de amizade.

Seguindo-se a hipótese encontrada na literatura (Engstrom \& Sedlacek, 1997) e a tendência dos dados encontrados neste estudo, os participantes do sexo masculino apresentaram uma representação mais negativa dos homossexuais. Da mesma forma, aqueles que revelaram menor contato com homossexuais apresentaram maior preconceito. Tais resultados, mais uma vez, corroboram a hipótese original e os estudos internacionais sobre o contato interpessoal e sua relação com gênero e julgamento negativo (Herek \& Capitanio, 1996; Stephan \& Stephan, 2001).

A hipótese do contato interpessoal (Allport, 1979) ressalta a importância e o poder que as experiências de coleguismo e amizade podem representar para a aceitação da homossexualidade sem julgamentos negativos. Os dados deste estudo revelam que o contato interpessoal parece desempenhar um papel predominante na criação de representações positivas sobre homossexuais (Fator 2).

Tentou-se analisar a interferência da área de estudos dos participantes (Curso), no entanto, contrariamente ao que encontraram Lacerda e colegas (2002), o presente estudo não obteve diferença significativa entre curso de origem dos estudantes com relação à expressão do preconceito nos três fatores da ECH, o que impossibilitou análises mais acuradas sobre esta variável.

\section{CONSIDERAÇÕES E LIMITAÇÕES}

Este estudo enfatiza a importância do contato interpessoal na dissolução de representações negativas, corroborando a idéia de que relações próximas constituem-se como uma via para a compreensão intergrupal. Apesar de satisfatório para o início do desenvolvimento de uma escala para avaliação de preconceito contra homossexuais, este trabalho possui algumas limitações e suscita alguns aspectos para futuras investigações.

Como esperado, principalmente na investigação entre a população de universitários, estima-se que houve perdas para a obtenção da auto-denominação "homossexual”. Tentou-se diminuir este problema com a utilização da escala de atração sexual e de orientação sexual (DeSouza, Solberg, \& Cerqueira-Santos, 2007). No entanto, os percentuais obtidos encontram-se abaixo do esperado para a população estudada. Além do 
mais, a amostra investigada limita a aplicação da escala para a população de universitários.

Não foi possível realizar análises mais acuradas por grupos de gays e lésbicas, uma vez que o tamanho amostral alcançado não foi estatisticamente suficiente. O número escasso de homossexuais auto-declarados inviabilizou a mensuração do grau de preconceito intragrupal (gays julgando gays). Assim, sugere-se a replicação deste estudo com amostra maior e mais diversificada. Além do mais, não foram realizadas análises sobre o julgamento dos grupos específicos de gays e lésbicas, na qual se pode encontrar diferenças significativas para explicar se o julgamento masculino diferere para gays e lésbicas, por exemplo, confirmando-se a hipótese sócio-histórica de Green (2000) e achados de outros estudos (Engstrom \& Sedlacek, 1997).

Não se mensurou a qualidade do contato interpessoal, mas apenas a freqüência de interações e o número de amigos gays ou lésbicas. Tal fato limita as conclusões do estudo, uma vez que desdobramentos da hipótese de Allport (1979) apontam para a qualidade da interação com um dos principais componetes da dissolução do preconceito. No entanto, a freqüência de contato com amigos não deixa de ser ser um dos indicadores apontados pelos estudos anteriores.

Apesar das limitações, este estudo enfatiza a importância do contato interpessoal na dissolução do preconceito, corroborando a idéia de que o conhecimento é uma poderosa ferramenta para a compreensão intergrupal. Ressalta-se a relevância desses achados no ambiente universitário, formador de profissionais e de opinião para a sociedade contemporânea e as suas implicações na implemantação de ações contra o preconceito.

\section{REFERÊNCIAS}

Allport, G. W. (1979). The nature of prejudice (Unabridged, $25^{\text {th }}$ anniversary ed.). Reading, MA: Addison-Wesley.

Anjos, G. (2002). Homossexualidade, direitos humanos e cidadania. Sociologias, 4(7), 222-252.

Bowen, A. M., \& Bourgeois, M. J. (2001). Attitudes toward lesbian, gay, and bisexual college students: The contribution of pluralistic ignorance, dynamic social impact, and contact theories. Journal of American College Health, 50(2), 91-96.

Brewer, M. B., \& Miller, N. (1984). Beyond the contact hypothesis: Theoretical perspectives on desegregation. Em N. Miller \& M. B. Brewer (Orgs.), Groups in contact: The psychology of desegregation (pp. 281-302). San Diego, CA: Academic Press.

D’Augelli, A. R., \& Rose, M. L. (1990). Homophobia in a university community: Attitudes and experiences of heterosexual freshmen. Journal of College Student Development, 31(6), 484491.

DeSouza, E., Cerqueira-Santos, E., \& Solberg, J. (2007). A crosscultural perspective on judgments of woman-to-woman sexual harassment: Does sexual orientation matter? Sex Roles, 56, 457-471.

Engstrom, C. M., \& Sedlacek, E. W. (1997). Attitudes of heterosexual students toward their gay male and lesbian peer. Journal of College Student Development, 38(6), 565-576.

Green, J. (2000). Além do carnaval: A homossexualidade masculina no Brasil do século XX. UNESP: São Paulo.

Hart, G., \& Wellings, K. (2002). Sexual behaviour and its medicalisation: In sickness and in health. British Medical Journal, 324, 896-900. Retirado em 02 de abril de 2006, do Medical Journal Database.

Herek, G. M. (1991). Stigma, prejudice, and violence against lesbians and gay men. Em J. C. Gonsiorek \& J. D. Weinrich (Orgs.), Homossexuality: Research implications for public policy (pp. 60-80). Newbury Park, CA; Sage.

Herek, G. M. (2000). The psychology of sexual prejudice. Current Directions in Psychological Science, 9, 19-22.

Herek, G. M. (2002). Gender gaps in public opinion about lesbians and gay men. Public Opinion Quarterly, 66, 40-66.

Herek, G. M. (2004). Beyond "homophobia": Thinking about sexual stigma and prejudice in the twenty-first century. Sexuality Research and Social Policy, 1(2), 6-24.

Herek, G., \& Capitanio, J. (1996). "Some of my best friends": Intergroup contact, concealable stigma, and heterosexuals' attitudes toward gay men and lesbians. Personality and Social Psychology Bulletin, 22, 412-424.

Kinsey, A., Pomeroy, W., \&, Martin, C. (1998). Sexual behavior in the human male. Indiana University Press. (Original publicado em 1948)

LaMar, L., \& Kite, M. (1998). Sex differences in attitudes toward gay men and lesbians: A multidimensional perspective. The Journal of Sex Research, 35, 189-196. Retirado em 22 de maio de 2006, de www.sexscience.org

Lacerda, M., Pereira, C., \& Camino, L. (2002). Um estudo sobre as formas de preconceito contra homossexuais na perspectiva das representações sociais. Psicologia: Reflexão e Crítica, 15(1), 165-178.

Liang, T. H. C., \& Alimo, C. (2005). The impact of white heterosexual students' interactions on attitudes toward lesbian, gay and bisexual people: A longitudinal study. Journal of College Student Development, 46(3), 237-250.

Meyer, I. H. (2003). Prejudice, social stress, and mental health in lesbian, gay, and bisexual populations: Conceptual issues and research evidence. Psychological Bulletin, 129(5), 674-697.

Simoni, J. M. (1996). Pathways to prejudice: Predicting students' heterosexist attitudes with demographics, self esteem, and contact with lesbians and gay men. Journal of College Student Development, 37, 68-76.

Stephan, W. G., \& Stephan, C. W. (2001). Improving intergroup relations. Thousand Oaks, CA: Sage. 
Theodore, P. S., \& Basow, S. A. (2000). Heterosexual masculinity and homophobia: A reaction to self? Journal of Homosexuality, 40, 31-48.

Whitley, B. (2001). Gender-role variables and attitudes toward homosexuality. Sex Roles, 45(11-12), 691-721.

Williamson, I. (2000). Internalized homophobia and health issues affecting lesbians and gay men. Health Education Research, 15(1), 97-107.

Wright, S. C., Aron, A., \& McLaughlin-Volpe, T. (1997). The extended contact effect: Knowledge of cross-group friendships and prejudice. Journal of Personality and Social Psychology, 73, 73-90.

Yarber, W. L., \& Lee, B. (1983). Heterosexuals’ attitudes toward lesbians and male homosexuality: Their affective orientation toward sexuality and sex guilt. Journal of College Health, 31, 203-208.

\section{Sobre os autores:}

Recebido: 15/11/2006

Última revisão: 06/12/2007

Aceite final: 18/12/2007

Elder Cerqueira-Santos: Psicólogo (UFS) e Doutor em Psicologia pela UFRGS/University of Nebraska - EUA.

Fernanda dos Santos Winter: Graduanda de Psicologia (UFRGS) e bolsista de Iniciação Científica.

Luís Adriano Salles: Graduando de Psicologia (UFRGS) e bolsista de Iniciação Científica.

José Luís Longo: Graduando de Psicologia (UFRGS) e bolsista de Iniciação Científica.

Maycoln L. M. Teodoro: Professor do Programa de Pós-Graduação da Unisinos, Doutor em Psicologia pela Albert-LudwigsUniversität, Freiburg, Alemanha.

Endereço para correspondência: Elder Cerqueira-Santos - Rua Ramiro Barcelos, 2600/104 - 90035-003 - Porto Alegre - RS -Brasil. Endereço eletrônico: eldercerqueira@yahoo.com.br. 